\title{
Prevalence and associated factors of depression among people with epilepsy in Mekelle, Tigray, Ethiopia, 2019.
}

Jemal Seid ( $\sim$ jemals283@gmail.com )

Mekelle University https://orcid.org/0000-0001-8754-3574

Kalayu Mebrahtu

Mekelle University College of Health Sciences

\section{Primary research}

Keywords: Comorbidity, Depression, Epilepsy, Outpatient, Mekelle

Posted Date: March 26th, 2020

DOI: https://doi.org/10.21203/rs.3.rs-17990/v1

License: (c) (i) This work is licensed under a Creative Commons Attribution 4.0 International License.

Read Full License 


\section{Abstract}

Background - Epilepsy is the world's most common neurological disorder, affecting approximately 50 million people worldwide and contributed to different psychiatric illness. Depression is one of the most frequent co morbid psychiatric disorders that affects the life of the patients. This comorbidity in people with epilepsy impose significant burdens on patients and their families. The study aimed to determine the prevalence of depression and associated factors among peoples with epilepsy in Mekelle, Ethiopia.

Methods - An institutional based cross-sectional study was conducted among systematically selected 296 people with epilepsy from April 15, 2019 - May 30, 2019. Depression was assessed by using the Patient health questionnaire (PHQs). The data were entered \& clean by using Epi Info 4.4 version. Statistical Package for Social Sciences version 25 was used for analysis. Factors with a p-value $<0.30$ in the bivariate logistic regression were entered into the multivariate model. A p-value of less than 0.05 was considered statistically significant.

Result - The prevalence of depression was found to be $34.8 \%$. Unable to read \& write (AOR= $0.400,95 \% \mathrm{Cl}$ : $0.162,0.986)$, long duration of the medication intake at least for 11 years ( $A O R=3.715,95 \% \mathrm{Cl}$ : $1.498,9.212$ ), absence of improvement with medication ( $A O R=0.216,95 \% \mathrm{Cl}: 0.101,0.460$ ), feeling of perceived stigma (AOR= $0.244,95 \% \mathrm{Cl}: 0.129,0.462)$, stress symptoms $(\mathrm{AOR}=0.452,95 \% \mathrm{Cl}$ : $0.220,0.928)$, were significantly associated with depression.

Conclusion - Nowadays depression among peoples with epilepsy is high.

Keywords:- Comorbidity, Depression, Epilepsy, Outpatient, Mekelle.

\section{Introduction}

Globally from the total people who suffer from epilepsy, $\approx 15-60 \%$ also experienced depression and/or anxiety disorder, $80 \%$ of them were exist in in low-income regions and these comorbidities are often underrecognized and undertreated (1-3). Depression is characterized by loss of interest, depressed mood, disturbance of sleep, problem in appetite and psychomotor activity, difficulty to concentrate or make decision, guilty or sinful feeling, easily tiredness and recurring thoughts of death or suicide (4).

The burden of comorbidity in people with epilepsy impose significant burdens on patients and their families (5). Several diseases, including depression, anxiety...\& others are up to eight times more common in people with epilepsy than in the general population \& negatively affect quality of life $(5,6)$. People with epilepsy (PWE) have been experienced more psychological disorders than general population (7).

Psychiatric comorbidities, especially depression (8-11) and anxiety disorders, seem to be the most frequent complications of epilepsy and reduce quality of life beyond seizures itself and affect the clinical course of epilepsy $(5,12-15)$. A population-based study in the United Kingdom indicated that $30.6 \%$ of PWE have depression (1). A Canadian study using data from the national population health survey 
demonstrated an association between epilepsy and lifetime major depression not only seriously affects PWE's health-related quality of life but also contributes to the high suicide rates among PWE compared with the general population, making it potentially life-threatening (2).

A systematic desk review and electronic web-based search conducted in united states show that prevalence of depression among patients with epilepsy was $32.71 \%$ and receiving polytherapy is the factor associated with epilepsy (16). A systematic review study conducted in different countries Asia revealed that $25 \%$ of PWE suffer from depression (9). A hospital based cross sectional study conducted in the north eastern part of India prevailed that $18 \%$ of total population experiences depression and Presence of partial seizures, frequent seizures, long duration of epilepsy and poor compliance to antiepileptic drug were significantly associated depression (17).

Another institutional based cross-sectional study conducted on patients attending psychiatric outpatient epilepsy clinic in psychiatry department of Amritsar city in India show that $40 \%$ of the participant suffer from depression (with $22.5 \%$ severe depression \& $17.5 \%$ moderate depression) and also being female \& on antiepileptic medication also factors associated with epilepsy (10).

A community based cross-sectional study among peoples with epilepsy in Brazil show that the prevalence of depression were $24.7 \%$ and low educational status, lifetime suicidal thought \& suicidal attempt were factors significantly associated with depression (18). A study conducted in Turkey by using beck depression inventory scale on 41 PWE show that $34.7 \%$ were suffer from depression, seizure frequency was the independent predictor of depression (19)

A cross-sectional study conducted in Rwanda show that $26.8 \%$ of the participant experience depression (20). Institution based quantitative cross-sectional study show that the prevalence of depression was $45.2 \%$ \& Lower educational status, early onset of illness, seizure frequency, poly-pharmacy and difficulties of adherence to anti-epileptic drugs (AEDs) were factors statistically associated with depression (21). A study conducted in Ethiopia show that the prevalence of depression among PWE were $43 \%$ \& Occupational status and perceived stigma were significantly associated with it (22).

An Institution-based cross-sectional study conducted at Emanuel Mental Specialized and Tikur Anbesa Hospitals, Addis Ababa, Ethiopia on a Samples of 422 epilepsy patients by using patient Health Questionnaire (PHQ)-9 show that $43.7 \%$ of the participant were experienced depression \& being female, single, having feeling of perceived stigma and medication nonadherence were factors significantly associated with it (23). Another Cross-sectional study conducted in selected public health facilities shows that $51.2 \%$ experiences depression Low educational status, Seizure frequencies $\geq 3$ per month, Age onset of epilepsy $\leq 11$ years, low anti-epileptic drug adherence and poor knowledge about epilepsy were the independent predictors of depression (24). A study conducted in Ethiopia show that $17.4 \%$ of PWE take alcohol (25) but there is limited study revealing association substance use with depression among PWE.

People with epilepsy (PWE) will experience depression at a higher rate, mainly two-three fold when compared to a general population (26). About 55\% lifetime prevalence for depression was Despite their 
relatively high prevalence with sever complication it remain unrecognized and untreated in many patients with epilepsy (27). In Ethiopia other factors like physical abuse and sexual abuse also were not addressed. Not only this but also there are no studies that assessed the magnitude and associated factors of depression among epileptic people in the Mekelle city of Tigray regional state, Ethiopia. Currently depression become a common comorbid problem for many cases including epilepsy. Giving good information about the comorbidity of depression with epilepsy is one of the main ways that reduce it \& promote healthy behaviors among peoples with epilepsy. This indicates that there is a need to identify the factor that leads depression in people with epilepsy. And also, it would be help health professionals to design strategies against the possible risk factors that increase depression among epileptic outpatients. Furthermore, the study results would give a little bit of information for policymakers to design and integrate comorbid screening approach with the general health service in order to minimize comorbidity. Since there is a paucity of information about depression and its associated factors among people with epilepsy, this study was aimed to assess the prevalence of depression \& its associated factor among patients with epilepsy in Mekelle town, Ethiopia, 2019.

\section{Methods}

\section{Study areas and period}

The study was conducted at the neurologic outpatient department of Ayder Comprehensive Specialized Hospital and Mekelle General Hospital located in Mekelle city, the Northern part of Ethiopia from April $15 / 2019$ - May 30/2019. Mekelle is the capital city of Tigray regional state \& located $780 \mathrm{~km}$ far in the north from Addis Ababa, with a total estimated population of 310, 436 of whom 140,067 (45.1\%) are men and $170,369(54.9 \%)$ are women (28). The city covers 109 square kilometers \& has one comprehensive specialized hospital (Ayder), three general hospital, nine health centers and several private hospital and clinics. Only three hospitals (Ayder Comprehensive Specialized Hospital, Mekelle General Hospital and Quiha General Hospital) gives outpatient neurological services but the former two gives the service in a separate manner \& the latter one gives neurological service with mental health services. In 2018/19 a total of 1103 epileptic patients are got services in the two hospitals (400 in ACSH \& 703 in MGH). The total monthly epilepsy caseloads in the two hospitals were more than 560 \& in both Hospital, epilepsy is a leading diagnosis of neurological problems.

\section{Study design}

An institution-based cross-sectional study was conducted.

\section{Source population and study population Source population}

All outpatients who were taking epileptic services in the neurology outpatient department of Ayder Compherensive Specialized Hospital \& Mekelle General Hospital. 


\section{Study population}

Outpatients he/she newly diagnosed as epileptics and they have been taking follow up treatment during the study period in ACSH \& MGH.

\section{Eligibility criteria}

\section{Inclusion criteria}

Newly diagnosed epileptic patients and outpatients who were in regular follow up treatment under the diagnosis of epilepsy with the age of 12 years old and above.

\section{Exclusion criteria}

Outpatients he/she was unable to communicate, aged from 12-17 years come alone was excluded from the study.

\section{Sample size and sampling procedure}

\section{Sample size}

Single population proportion formula was used to determine the maximum number of samples required for this study. The study conducted in Ethiopia indicated that the prevalence of depression among epileptic patient was $43.8 \%(23)$.

The final sample size for this study was determined by $n=(Z a / 2)^{2} P(1-P) / D^{2}$

Where, $\mathrm{n}=$ the required sample size

$Z$ = standard score corresponding to a $95 \%$ confidence interval

$\mathrm{P}=$ assumed a proportion of prevalence of perceived stigma among people with epilepsy

$D=$ the margin of error (precision) $5 \%$

Then, $\mathrm{n}=(1.96)^{2} \mathrm{x}(0.438)(0.562) /(0.05)^{2}=378$

The total patient in the two are 1103 (400 in ACSH \& 703 in MGH). Since the $N$ is $<10,000$, use correction formula

$n f=n / 1+(n / N)$. Where, $N=$ total population of people with epilepsy

$\mathrm{Nf}=$ final sample size

$\mathrm{nf}=378 / 1+(378 / 1103)=282$ and considering the non-respondent rate of $5 \%$ it becomes 296 . Finally, the population was proportionally allocated in the following way. 


\section{Sampling technique and procedure}

A systematic random sampling technique was used to select participants from both hospitals. The $k$ value was calculated by dividing the total population to total sample size $(1103 / 296 \approx 3)$. The data was collected in six-week duration; the total patient follows in one month were obtained by calculating the average of the previous year of twelve-month. The required sample size was proportionally allocated for each hospital. Finally, every 3nd person the data collector was selected the patient from the respected hospital.

\section{Data collection}

Data were collected by trained 2 BSc degree health professionals by using interviewer-administered pretested questionnaire. The questionnaire consisted of the socio-demographic characteristics (age, sex, marital status, educational level \& others ) and questions that address the factors associated with depression. Depression was assessed by using pateint health questionnaires (PHQs).

\section{Data collection procedure}

PHQ-9 is one of the most widely used self-report measures of depression. It is a reliable and valid measure of depression in a range of cultural groups and has been validated with psychiatric and nonpsychiatric populations with Cronbach's a range from 0.84-0.915 in most of the countries including Africa $(29,30)$. In Ethiopia, it was also validated in Afaan Oromo Cronbach's alpha, 0.84 (31). It consists of 9 items, and each item four-point Likert scores (not at all '0'up to nearly every day ' 3 ') to describe a specific behavioral manifestation of depression. A score $\geq 10$ are considered as having depression (32).

Perceived stigma was measured by using the KSSE which was developed and validated in Kilifi, Kenya with high internal consistency, Cronbach's $\alpha$ of 0.91 (33) and adopted to Ethiopia $(34,35)$. It is a simple three-point Likert scoring system scored as "not at all" (score of 0 ), "sometimes" (score of 1 ), and "always" (score of 2). It has fifteen items and a total score was calculated by addition of all item scores. The lowest score was 0 and the highest was 30 . The 66th percentile was used to categorize the scores (3336).

Social support was assessed by Oslo 3-item social support scale, Oslo 3-item social support scale is a 3item questionnaire commonly used to asses' social support. The scale asks about the ease of getting help from neighbors, the number of people the subjects can count on when there are serious problems, and the level of concern people show in what the subject is doing. A sum-index is obtained by adding the raw scores of the three items. The range is $3-14$. The scores are interpreted as ; $3-8$ (poor social support), 9-11 (moderate social support), and 12-14 (strong social support) $(37,38)$.

For screening of substance use a modified form of ASSIST, developed by World Health Organization (WHO) an international group of substance abuse researchers to detect and manage substance use and related problems in primary and general medical care settings was used. 
To assess anxiety \& stress GAD-7 and modified form of DASS respectively was used.

GAD-7 is mostly used tool for screening of anxiety by remembering the past 2 weeks. It also contains 7 items with a four Likert item. The tool is cross-culturally validated with the internal consistency of Cronbach's a $=0.915$ (39). A score greater than or equal to 10 is considered as having moderate to severe anxiety (32).

The DASS 21 is a 21 -item self-report questionnaire designed to measure the severity of a range of symptoms common to both Depression and Anxiety stress. But for this study I was taken the modified form of DASS-21 contain 7 items only, which scored from 0 (did not apply to me at all over the last week) to 3 (applied to me very much or most of the time over the past week) with the main focus on to assess the severity of the core symptoms Stress only. This tool is cross-culturally valid measures in China with a Cronbach alpha of $=0.86$ and adopted in Ethiopia (40). A score $>9$ is considered as having moderate to severe stress. For that PHQ-9, GAD-7 \& the modified form of DASS-21 scores $>9$ and the patients become voluntary they were linked to psychiatry outpatient department for further screening and management.

\section{Operational definitions}

Anxiety:- According to Generalized Anxiety Disorder-7 scale people with epilepsy, those who scored $>9$ was concluded to have anxiety (32).

Comorbidity:- is defined as a greater than coincidental presence of two disorders in the same person without inferring a causal relation (41).

Depression:- According to Patient Health Questionnaire-9 scale people with epilepsy, those who score $>9$ was concluded to have depression $(29,31,32)$

Nonstigmatized patient:- People with epilepsy who score less than or equal to the 66th percentile of Kilifi stigma scale of epilepsy (33-36).

People with epilepsy:- Peoples who experienced At least two unprovoked (or reflex) seizures occurring greater than 24 hours apart (42).

Perceived stigmatized patient:- People with epilepsy who score above the 66th percentile of Kilifi stigma scale of epilepsy (33-36).

Physical abuse:- Those acts commission by other persons that cause actual physical harm or have the potential for harm on people with epilepsy (43).

Sexual abuse:- Those acts where another person uses an epileptic patient for sexual gratification forcefully (43).

Stress:- According to the modified form of depression, anxiety \& stress scale people with epilepsy, those who scored $>9$ was concluded to have stress (40). 
Suicidal ideation:- After starting the illness any thoughts about self-harm with deliberate consideration or planning of possible techniques of causing one's own death (44).

Suicidal attempt:- After starting epilepsy any attempt to end one's own life (44).

\section{Data quality assurance}

To keep the quality of the study's data, the questionnaires were translated into Tigrigna (local language) by professional Tigrigna speaker individuals who had experience and knowledge in mental illness and back-translation to English was performed by a senior specialist who had clinical experiences in institutions for its simplicity and clarity for use.

Two weeks before the actual data collection pre-test was carried out on $5 \%$ of the total sample of people with epilepsy in Qiuha General Hospital to ascertain clarity, feasibility, and applicability of the study tools, to estimate the proper time required for answering the questionnaire, and to identify obstacles that may be faced during data collection. The sample in the pre-test was excluded from the entire sample of research work.

In addition, the principal investigator gave a one-day training for data collectors on the techniques of data collection. Confidentiality of the participants throughout the whole process of data collection was maintained. The collected data were checked daily for completeness.

\section{Data analysis procedure}

Data were entered and cleaned by using Epi-info version 4.4.3.1 and transferred to Statistical Package for Social Sciences version 25 (SPSS-25) for further analysis. Descriptive statistical analysis was used to estimate the frequencies and percentages of the variables. Binary logistic regression and adjusted odds ratio with a $95 \%$ confidence interval were used to identify the associated factors of the outcome variable. All factors with a $p$-value $<0.30$ in the bivariate logistic regression was directly entered into the multivariate model. Finally, all P-value less than 0.05 will be considered statistically significant.

\section{Ethical Consideration}

The ethical approval was obtained from the ethical review board of Mekelle University, College of Health science. Verbal and then written consent form was taken from each participant. For those aged from 1217 , a written assent was taken from their relatives that s/he comes with them. An information sheet was attached to each questionnaire to provide study details \& to tell the rights of the participants. All the collected data was used for the purpose of this study only. Hard copy completed questionnaires and computer data was kept confidentially.

\section{Results}

A total of 296 patients with epilepsy were recruited in the study. The overall response rate was $100 \%$.

Sociodemographic Characteristics. 
All of the respondents were in the age group of 13-65 years with the mean, age of $31.6 \pm 13.04$.SD. The median \& mode age of respondent was 29 and 24 respectively. Among all participants, 163(55.1\%) were male, $186(62.8 \%$ ) were live in urban area \& geographically $268(90.5)$ were Tigran in ethnicity. Majority of the participant $239(80.7 \%)$ were orthodox in religion, $96(32.4 \%)$ were unable to read \& write, $95(32.1 \%)$ were married, 135 (45.6\%) had no any specified monthly income and $162(54.7 \%)$ were had moderate social support (Table 1). 
Table 1

Distribution of study subjects by socio demographic factors peoples with epilepsy $(n=296)$ on follow up at Ayder comprehensive specialized hospital and Mekelle hospital, Mekelle, Tigray, Ethiopia, 2019.

\begin{tabular}{|c|c|c|c|}
\hline & Variables & Frequency & Percentage \\
\hline \multirow[t]{5}{*}{ Age } & $12-17$ years & 34 & 11.5 \\
\hline & $18-24$ years & 77 & 26.0 \\
\hline & $24-34$ years & 70 & 23.6 \\
\hline & $35-44$ years & 63 & 21.3 \\
\hline & $>44$ years & 52 & 17.6 \\
\hline \multirow[t]{2}{*}{ Sex } & Male & 163 & 55.1 \\
\hline & Female & 133 & 44.9 \\
\hline \multirow[t]{2}{*}{ Residency } & Urban & 186 & 62.8 \\
\hline & Rural & 110 & 37.2 \\
\hline \multirow[t]{4}{*}{ Ethnicity } & Tigray & 268 & 90.5 \\
\hline & Amhara & 11 & 3.7 \\
\hline & Afar & 16 & 5.4 \\
\hline & Other & 1 & .3 \\
\hline \multirow[t]{4}{*}{ Religion } & Orthodox & 239 & 80.7 \\
\hline & Catholic & 4 & 1.4 \\
\hline & Protestant & 4 & 1.4 \\
\hline & Muslim & 49 & 16.5 \\
\hline \multirow[t]{6}{*}{ Educational status } & Unable to read \& write & 96 & 32.4 \\
\hline & Primary 1-8 & 84 & 28.4 \\
\hline & Secondary 9-12 & 48 & 16.2 \\
\hline & Techniques & 8 & 2.7 \\
\hline & Diploma & 9 & 3.1 \\
\hline & first degree and above & 51 & 17.2 \\
\hline \multirow[t]{2}{*}{ Marital status } & Married & 95 & 32.1 \\
\hline & Single & 150 & 50.7 \\
\hline
\end{tabular}




\begin{tabular}{|c|c|c|c|}
\hline & Variables & Frequency & Percentage \\
\hline & Divorced & 22 & 7.4 \\
\hline & Widowed & 26 & 8.8 \\
\hline & Other & 3 & 1.0 \\
\hline \multirow[t]{8}{*}{ Employment } & No & 41 & 13.9 \\
\hline & Student & 69 & 23.3 \\
\hline & Farmer & 32 & 10.8 \\
\hline & house wife & 56 & 18.9 \\
\hline & Government & 16 & 5.4 \\
\hline & Private & 33 & 11.1 \\
\hline & Merchant & 24 & 8.2 \\
\hline & Others & 25 & 8.4 \\
\hline \multirow[t]{5}{*}{ Monthly income } & No & 135 & 45.6 \\
\hline & $301-600$ & 23 & 7.8 \\
\hline & $<300$ & 21 & 7.1 \\
\hline & $601-1000$ & 24 & 8.1 \\
\hline & $>1000$ & 93 & 31.4 \\
\hline \multirow[t]{3}{*}{ Social support } & Low & 72 & 24.3 \\
\hline & Moderate & 162 & 54.8 \\
\hline & High & 62 & 20.9 \\
\hline
\end{tabular}

Description of respondents by clinical factors

From the total 296 respondents, $120(40.5 \%)$ were start epilepsy at the age of 18 \& above, 135(45.6\%) were live with epilepsy for at least 11 years and $134(45.3 \%)$ were experienced seizure related physical trauma. $163(55.1 \%)$ of the participant were reported that they experience at most 2 seizures in a month \& $82(27.7 \%)$ experience seizure frequency 3-5 time per month. Majority of the respondent $216(73.0 \%)$ were on monotherapy, $88(28.7 \%)$ were taken the medication for more than 11 years and $243(82.1 \%)$ were had good improvement with medication (Table 2). 
Table 2

Distribution of study subjects by clinical related factors of peoples with epilepsy $(n=296)$ on follow up at Ayder comprehensive specialized hospital and Mekelle hospital, Mekelle, Tigray, Ethiopia, 2019.

\begin{tabular}{|c|c|c|c|}
\hline & Variables & Frequency & Percentage \\
\hline \multirow[t]{4}{*}{ Age of onset } & $<6$ years & 32 & 10.8 \\
\hline & $6-11$ years & 76 & 25.7 \\
\hline & $12-17$ years & 68 & 23.0 \\
\hline & $18 \&$ above years & 120 & 40.5 \\
\hline \multirow[t]{4}{*}{ Total duration of the illness } & $\leq 1$ year & 11 & 3.7 \\
\hline & $2-5$ years & 64 & 21.6 \\
\hline & $6-10$ years & 86 & 29.1 \\
\hline & 11 years or above & 135 & 45.6 \\
\hline \multirow[t]{4}{*}{ Number of seizures } & $\leq 2$ per month & 163 & 55.1 \\
\hline & 3-5 per month & 82 & 27.6 \\
\hline & $6-10$ per 6 months & 41 & 13.9 \\
\hline & $\geq 11$ per year & 10 & 3.4 \\
\hline \multirow[t]{2}{*}{ Seizures related physical trauma } & No & 162 & 54.7 \\
\hline & Yes & 134 & 45.3 \\
\hline \multirow[t]{2}{*}{ Number of AEDs } & Monotherapy & 216 & 73.0 \\
\hline & Polytherapy & 80 & 27.0 \\
\hline \multirow[t]{5}{*}{ Length of time with medication } & $0-11$ month & 31 & 10.5 \\
\hline & Less than 2 years & 40 & 13.5 \\
\hline & $2-5$ years & 85 & 28.7 \\
\hline & $6-10$ years & 52 & 17.6 \\
\hline & 11 or more years & 88 & 29.7 \\
\hline \multirow[t]{2}{*}{ Improvement with medication } & No & 53 & 17.9 \\
\hline & Yes & 243 & 82.1 \\
\hline \multirow[t]{2}{*}{ Medication related side effect. } & No & 207 & 69.9 \\
\hline & Yes & 89 & 30.1 \\
\hline
\end{tabular}




\begin{tabular}{|c|c|c|c|}
\hline & Variables & Frequency & Percentage \\
\hline \multirow[t]{2}{*}{ Life time substance use history } & No & 220 & 74.3 \\
\hline & Yes & 76 & 25.7 \\
\hline \multirow[t]{2}{*}{ Substance use history in the past 3 months. } & No & 267 & 90.2 \\
\hline & Yes & 29 & 9.8 \\
\hline \multirow[t]{2}{*}{ Presence of chronic medical illness } & No & 250 & 84.5 \\
\hline & Yes & 46 & 15.5 \\
\hline \multirow[t]{2}{*}{ Perceived stigma } & No & 193 & 65.2 \\
\hline & Yes & 103 & 34.8 \\
\hline \multirow[t]{2}{*}{ Anxiety } & No & 200 & 67.6 \\
\hline & Yes & 96 & 32.4 \\
\hline \multirow[t]{2}{*}{ Stress } & No & 227 & 76.7 \\
\hline & Yes & 69 & 23.3 \\
\hline \multirow[t]{2}{*}{ History of physical abused } & No & 284 & 95.9 \\
\hline & Yes & 12 & 4.1 \\
\hline \multirow[t]{2}{*}{ History of sexual abused } & No & 293 & 99.0 \\
\hline & Yes & 3 & 1.0 \\
\hline \multirow[t]{2}{*}{ Suicidal attempt history } & No & 285 & 96.3 \\
\hline & Yes & 11 & 3.7 \\
\hline \multirow[t]{2}{*}{ Presence of suicidal wish } & No & 238 & 80.4 \\
\hline & Yes & 58 & 19.6 \\
\hline
\end{tabular}

Description of Respondents Patient's Contagion Belief, and Causal Belief of Epilepsy.

Regarding the cause of epilepsy, 94(31.8\% ) were believe that it is caused by walks around garbage, dumps, ashes, walking along a river \& $69(23.3 \%)$ were not know. Out of the total participant $181(61.1 \%)$ were believe that epilepsy is a mental illness, 263 (88.9) were believe that epilepsy is treatable (Table 3). 
Table 3

Distribution of study subjects by ( causal, contagion, heritability, treatability \& mental illness Belief) of people with epilepsy $(n=296)$ up at Ayder on- follow comprehensive specialized hospital and Mekelle hospital, Mekelle, Tigray, Ethiopia, 2019.

\begin{tabular}{|c|c|c|c|}
\hline & Variables & Frequency & Percentage \\
\hline \multirow{7}{*}{$\begin{array}{l}\text { Cause of } \\
\text { epilepsy }\end{array}$} & I don't know & 69 & 23.3 \\
\hline & spiritual possession & 39 & 13.2 \\
\hline & evil eye & 19 & 6.4 \\
\hline & family history & 32 & 10.8 \\
\hline & Pathogens & 6 & 2.0 \\
\hline & sinful act & 37 & 12.5 \\
\hline & $\begin{array}{l}\text { walks around garbage, dumps, ashes, walking along a } \\
\text { river ....... }\end{array}$ & 94 & 31.8 \\
\hline \multirow[t]{2}{*}{ Contagious } & No & 255 & 86.1 \\
\hline & Yes & 41 & 13.9 \\
\hline \multirow[t]{2}{*}{ Heritable } & No & 235 & 79.4 \\
\hline & Yes & 61 & 20.6 \\
\hline \multirow[t]{2}{*}{ Mental illness } & No & 115 & 38.9 \\
\hline & Yes & 181 & 61.1 \\
\hline \multirow[t]{2}{*}{ Treatable } & No & 33 & 11.1 \\
\hline & Yes & 263 & 88.9 \\
\hline \multirow{4}{*}{$\begin{array}{l}\text { By what } \\
\text { means? }\end{array}$} & Hole water & 1 & 0.3 \\
\hline & Traditional treatment & 2 & 0.6 \\
\hline & Modern medicine & 222 & 75.0 \\
\hline & Hole water \& modern medicine & 41 & 14.0 \\
\hline
\end{tabular}

Depression Scores of Participants.

Overall, the prevalence of perceived stigma was found to be $34.8 \%$. Regarding the proportion of depression toward each item, most of the participants 213 (71.9\%) reported that they Trouble falling or staying asleep, or sleeping too much, $210(70.9 \%)$ were reported feeling down, depressed or hopeless and 197 (66.6\%) also reported that having little interest or pleasure in doing things (Table 4). 
Table 4

Proportion of responses to PHQ-9 by study participants of patients with epilepsy ( $n=296)$ on follow up at Ayder comprehensive specialized hospital and Mekelle hospital, Mekelle, Tigray, Ethiopia, 2019.

\begin{tabular}{|c|c|c|c|c|c|c|c|c|c|}
\hline & \multirow[t]{2}{*}{ Scale } & \multicolumn{2}{|c|}{ Not at all } & \multicolumn{2}{|c|}{ Several days } & \multicolumn{2}{|c|}{$\begin{array}{l}\text { More than } \\
\text { half of the } \\
\text { days. }\end{array}$} & \multicolumn{2}{|c|}{ Every day } \\
\hline & & $n / 296$ & $\%$ & $n / 296$ & $\%$ & $\mathrm{n} / 296$ & $\%$ & $\mathrm{n} / 296$ & $\%$ \\
\hline 1 & $\begin{array}{l}\text { Little interest or pleasure in } \\
\text { doing things }\end{array}$ & 99 & 33.4 & 111 & 37.5 & 63 & 21.3 & 23 & 7.8 \\
\hline 2 & $\begin{array}{l}\text { Feeling down, depressed or } \\
\text { hopeless }\end{array}$ & 86 & 29.1 & 128 & 43.2 & 67 & 22.6 & 15 & 5.1 \\
\hline 3 & $\begin{array}{l}\text { Trouble falling or staying } \\
\text { asleep, or sleeping too much }\end{array}$ & 82 & 27.7 & 136 & 46.2 & 63 & 21.3 & 14 & 4.8 \\
\hline 4 & $\begin{array}{l}\text { Feeling tired or having little } \\
\text { energy }\end{array}$ & 101 & 34.1 & 121 & 40.9 & 59 & 19.9 & 15 & 5.1 \\
\hline 5 & Poor appetite or overeating & 126 & 42.6 & 102 & 34.5 & 54 & 18.2 & 14 & 4.7 \\
\hline 6 & $\begin{array}{l}\text { Feeling bad about yourself - } \\
\text { or that you are a failure or } \\
\text { have let yourself or your } \\
\text { family down }\end{array}$ & 143 & 48.3 & 100 & 33.8 & 46 & 15.5 & 7 & 2.4 \\
\hline 7 & $\begin{array}{l}\text { Trouble concentrating on } \\
\text { things, such as reading the } \\
\text { newspaper or watching } \\
\text { television }\end{array}$ & 133 & 44.9 & 90 & 30.4 & 61 & 20.6 & 12 & 4.1 \\
\hline 8 & $\begin{array}{l}\text { Moving or speaking so } \\
\text { slowly that other people } \\
\text { could have noticed, or the } \\
\text { opposite }\end{array}$ & 205 & 69.3 & 77 & 26.0 & 14 & 4.7 & 0 & 0 \\
\hline 9 & $\begin{array}{l}\text { Thoughts that you would be } \\
\text { better off dead or of hurting } \\
\text { yourself in some way }\end{array}$ & 196 & 66.2 & 90 & 30.4 & 10 & 3.4 & 0 & 0 \\
\hline
\end{tabular}

The lowest score of the data was 0 and the highest score was 19. The mean, median and mode the respondent was 7.2, 6, 5 respectively. Scores above 9 were considered to show the PWE who had depression. Accordingly, out of the 296 study subjects recruited in the study, 103 (34.8\%) scored above 9 as measured by the PHQs.

Factors associated with depression

Bivariate analyses were done between depression and response variables of socio-demographic variables ( Age, Residency, educational status, Marital status, employment \& social support), Clinical factors ( total 
duration of the illness, seizure frequency, number of AEDs, side effect of medication, seizure related trauma, feeling perceived stigma, anxiety symptoms, stress symptoms and history of suicidal attempt) and patients belief factors (contagious belief, heritability belief, perceived as a mental illness \& treatability belief ) were found to be significantly associated with depression at $p$ value less than 0.3 . All individual factors $<0.30$ at bivariate analyses were entered to multivariate logistic regression for further analysis.

Accordingly, Unable to read \& write $(A O R=0.400,95 \% \mathrm{Cl}: 0.162,0.986)$, long duration of the medication intake at least for 11 years ( $A O R=3.715,95 \% \mathrm{Cl}$ : 1.498, 9.212), poor improvement with medication (AOR $=0.216,95 \% \mathrm{Cl}: 0.101,0.460)$, feeling of perceived stigma ( $\mathrm{AOR}=0.244,95 \% \mathrm{Cl}: 0.129,0.462)$, stress symptoms $(A O R=0.452,95 \% \mathrm{Cl}: 0.220,0.928)$, were significantly associated with depression ( Table 5). 
Table 5

Factors associated with depression in people with epilepsy (bivariate and multivariate analysis) for the study of the prevalence of depression and associated factors among epileptic patients in ACSH \& MGH, 2019.

\begin{tabular}{|c|c|c|c|c|c|}
\hline \multirow[b]{2}{*}{ Variables } & \multicolumn{2}{|c|}{ Depression } & \multicolumn{2}{|c|}{ Bivariate } & \multirow{2}{*}{$\begin{array}{l}\text { Multivariate analysis } \\
\text { AOR }(95 \%, \mathrm{Cl})\end{array}$} \\
\hline & No & Yes & $\begin{array}{l}\mathrm{P} \text { - } \\
\text { value }\end{array}$ & $\operatorname{COR}(95 \%, \mathrm{Cl})$ & \\
\hline \multicolumn{6}{|l|}{ Age } \\
\hline $12-17$ years & 23 & 11 & 1 & & \\
\hline $18-24$ years & 52 & 25 & 0.588 & $\begin{array}{l}1.298(0.505 \\
3.338)\end{array}$ & $1.392(0.279,6.953)$ \\
\hline $24-34$ years & 37 & 33 & 0.502 & $\begin{array}{l}1.305(0.600 \\
2.837)\end{array}$ & $1.136(0.301,4.285)$ \\
\hline $35-44$ years & 43 & 20 & $0.025^{\star}$ & $\begin{array}{l}2.421(1.119 \\
5.238)\end{array}$ & $2.261(0.7007 .305)$ \\
\hline$>45$ years & 38 & 14 & 0.573 & $\begin{array}{l}1.262 \text { (0.561, } \\
2.839)\end{array}$ & $1.517(0.5234 .400)$ \\
\hline \multicolumn{6}{|l|}{ Sex } \\
\hline Male & 102 & 61 & 1 & & \\
\hline Female & 91 & 42 & 0.294 & $\begin{array}{l}1.296(0.799 \\
2.103)\end{array}$ & \\
\hline \multicolumn{6}{|l|}{ Residency } \\
\hline Urban & 125 & 61 & 0.348 & $\begin{array}{l}1.266(0.774 \\
2.069)\end{array}$ & \\
\hline Rural & 68 & 42 & 1 & & \\
\hline \multicolumn{6}{|l|}{ Educational status } \\
\hline Unable to read \& write & 58 & 38 & 0.300 & $\begin{array}{l}0.723(0.391 \\
1.336)\end{array}$ & $\begin{array}{l}0.400 \\
)^{\star \star}\end{array}$ \\
\hline Primary 1-8 & 57 & 27 & 0.809 & $\begin{array}{l}0.916(0.449 \\
1.869)\end{array}$ & $0.692(0.2551 .877)$ \\
\hline Secondary 9-12 & 30 & 18 & 0.566 & $\begin{array}{l}1.526(0.360 \\
6.474)\end{array}$ & $3.189(0.61516 .543)$ \\
\hline
\end{tabular}

Note $*$ :- Significantly associated at $p<0.30 \& *$ :- Stastically significant at $p<0.05$

P-value of Hosmer and Lemeshow goodness of fit test was $=0.593$ 


\begin{tabular}{|c|c|c|c|c|c|}
\hline \multirow[b]{2}{*}{ Techniques } & \multicolumn{2}{|c|}{ Depression } & \multicolumn{2}{|c|}{ Bivariate } & \multirow{2}{*}{$\begin{array}{l}\text { Multivariate analysis } \\
0.335(0.0532 .106)\end{array}$} \\
\hline & 4 & 4 & 0.714 & $\begin{array}{l}0.763(0.180 \\
3.237)\end{array}$ & \\
\hline Diploma & 6 & 3 & 0.090 & $\begin{array}{l}0.522(0.246 \\
1.106)\end{array}$ & $0.348(0.1151 .055)$ \\
\hline First degree and above & 38 & 13 & 1 & & 1 \\
\hline \multicolumn{6}{|l|}{ Marital status } \\
\hline Married & 66 & 29 & 1 & & \\
\hline Single & 94 & 56 & 0.999 & $0.000(0.000,-)$ & \\
\hline Divorced & 15 & 7 & 0.999 & $0.000(0.000,--)$ & \\
\hline Widowed & 18 & 8 & 0.999 & $0.000(0.000,--)$ & \\
\hline Other & 0 & 3 & 0.999 & $0.000(0.000,--)$ & \\
\hline \multicolumn{6}{|l|}{ Employment } \\
\hline No & 25 & 16 & 0.655 & $\begin{array}{l}0.833(0.375 \\
1.854)\end{array}$ & $1.273(0.4723 .432)$ \\
\hline Student & 45 & 24 & 0.492 & $\begin{array}{l}0.710(0.268 \\
1.885)\end{array}$ & 1.695 (0.5035.715) \\
\hline Farmer & 22 & 10 & 0.705 & $\begin{array}{l}1.172(0.516 \\
2.663)\end{array}$ & $1.628(0.5844 .540)$ \\
\hline House wife & 32 & 24 & 0.744 & $\begin{array}{l}1.215(0.377 \\
3.916)\end{array}$ & $1.470(0.3615 .986)$ \\
\hline Governmental & 9 & 7 & $0.104^{*}$ & $\begin{array}{l}0.421(0.148 \\
1.195)\end{array}$ & $2.405(0.1071 .532)$ \\
\hline Private & 26 & 7 & 0.903 & $\begin{array}{l}0.937(0.332 \\
2.646)\end{array}$ & 1.971 (0.5277.372) \\
\hline Others/day labor & 15 & 9 & $0.213^{*}$ & $\begin{array}{l}0.493(0.162 \\
1.500)\end{array}$ & $0.592(0.1542 .279)$ \\
\hline Merchant & 19 & 6 & 1 & & \\
\hline \multicolumn{6}{|l|}{ Monthly income } \\
\hline No & 95 & 44 & 0.836 & $\begin{array}{l}1.103(0.435 \\
2.797)\end{array}$ & $0.708(0.2062 .432)$ \\
\hline
\end{tabular}

Note $*$ :- Significantly associated at $p<0.30 \& *$ :- Stastically significant at $p<0.05$

P-value of Hosmer and Lemeshow goodness of fit test was $=0.593$ 


\begin{tabular}{|c|c|c|c|c|c|}
\hline \multirow[b]{2}{*}{$<300$} & \multicolumn{2}{|c|}{ Depression } & \multicolumn{2}{|c|}{ Bivariate } & \multirow{2}{*}{$\begin{array}{l}\text { Multivariate analysis } \\
2.655(0.8028 .787)\end{array}$} \\
\hline & 15 & 8 & $0.183^{*}$ & $\begin{array}{l}1.880(0.743 \\
4.760)\end{array}$ & \\
\hline $301-600$ & 11 & 10 & $0.213^{*}$ & $\begin{array}{l}1.750(0.726 \\
4.219)\end{array}$ & $1.395(0.4364 .461)$ \\
\hline $601-1000$ & 13 & 11 & 0.958 & $\begin{array}{l}0.985(0.560 \\
1.732)\end{array}$ & $1.265(0.5612 .853)$ \\
\hline$>1001$ & 63 & 30 & 1 & & \\
\hline \multicolumn{6}{|l|}{ Social support } \\
\hline Low & 44 & 28 & 0.587 & $\begin{array}{l}0.853(0.481 \\
1.513)\end{array}$ & $1.143(0.5402 .420)$ \\
\hline Moderate & 105 & 57 & $0.232^{\star}$ & $\begin{array}{l}0.643(0.311 \\
1.327)\end{array}$ & $.819(0.3162 .123)$ \\
\hline High & 44 & 18 & 1 & & \\
\hline \multicolumn{6}{|l|}{ Age of onset } \\
\hline$<6$ years & 20 & 12 & 1 & & 1 \\
\hline $6-11$ years & 44 & 32 & 0.657 & $\begin{array}{l}1.212(0.519 \\
2.831)\end{array}$ & $1.128(0.3263 .899)$ \\
\hline $12-17$ years & 50 & 18 & $0.264^{\star}$ & $\begin{array}{l}0.600(0.245 \\
1.470)\end{array}$ & $1.602(0.5964 .306)$ \\
\hline 18 \& above years & 79 & 41 & 0.725 & $\begin{array}{l}0.865(0.385 \\
1.942)\end{array}$ & $0.854(0.3242 .248)$ \\
\hline \multicolumn{6}{|l|}{ Total duration } \\
\hline$\leq 1$ year & 8 & 3 & 1 & & \\
\hline $2-5$ years & 43 & 21 & 0.581 & $\begin{array}{l}0.680(0.172 \\
2.683)\end{array}$ & \\
\hline $6-10$ years & 55 & 31 & 0.704 & $0.885(0.4721 .661)$ & \\
\hline 11 years or above & 87 & 48 & 0.941 & $1.022(0.5811 .795)$ & \\
\hline \multicolumn{6}{|l|}{ Seizures frequency } \\
\hline$\leq 2$ per month & 112 & 51 & 0.568 & $0.683(0.1852 .526)$ & \\
\hline $3-5$ per month & 54 & 28 & 0.714 & 0.778 (0.2032.985) & \\
\hline
\end{tabular}

Note $*$ :- Significantly associated at $p<0.30 \&_{* \star}$ :- Stastically significant at $p<0.05$

P-value of Hosmer and Lemeshow goodness of fit test was $=0.593$ 


\begin{tabular}{|c|c|c|c|c|c|}
\hline \multirow[b]{2}{*}{$6-10$ per 6 months } & \multicolumn{2}{|c|}{ Depression } & \multicolumn{2}{|c|}{ Bivariate } & \multirow[t]{2}{*}{ Multivariate analysis } \\
\hline & 21 & 20 & 0.619 & $1.429(0.3505 .825)$ & \\
\hline 11 or above per year & 6 & 4 & 1 & & \\
\hline \multicolumn{6}{|l|}{ No of AEDs } \\
\hline Monotherapy & 142 & 74 & 1 & & \\
\hline Polytherapy & 51 & 29 & 0.750 & $\begin{array}{l}0.916(0.536 \\
1.566)\end{array}$ & \\
\hline \multicolumn{6}{|l|}{ Treatment duration } \\
\hline $0-11$ month & 18 & 13 & $0.132^{*}$ & 1 & 1 \\
\hline less than 2 years & 29 & 11 & & $1.926(0.8204 .523)$ & $2.850(0.9278 .761)$ \\
\hline $2-5$ years & 54 & 31 & 0.979 & $1.011(0.4382 .338)$ & $1.975(0.6535 .972)$ \\
\hline $6-10$ years & 28 & 24 & $0.195^{\star}$ & $1.531(0.8042 .916)$ & $1.820(0.7644 .337)$ \\
\hline 11 or more years & 64 & 24 & $0.024^{\star}$ & $2.286(1.1134 .692)$ & $\begin{array}{l}3.715(1.498 \\
9.212)^{\star \star}\end{array}$ \\
\hline \multicolumn{6}{|c|}{ Adherence with medication } \\
\hline No & 20 & 33 & $0.000 *$ & $0.245(0.1320 .456)$ & $\begin{array}{l}0.216(0.101 \\
0.460)^{\star \star}\end{array}$ \\
\hline Yes & 173 & 70 & 1 & & 1 \\
\hline \multicolumn{6}{|l|}{ Side effect } \\
\hline No & 137 & 70 & 1 & & \\
\hline Yes & 56 & 33 & 0.589 & $0.867(0.5171 .455)$ & \\
\hline \multicolumn{6}{|c|}{ Substance use in life time } \\
\hline No & 143 & 77 & 1 & & \\
\hline Yes & 50 & 26 & 0.901 & $1.036(0.5981 .793)$ & \\
\hline \multicolumn{6}{|c|}{$\begin{array}{l}\text { Substance use within } 3 \\
\text { months }\end{array}$} \\
\hline No & 175 & 92 & 1 & & \\
\hline Yes & 18 & 11 & 0.709 & $0.860(0.3901 .898)$ & \\
\hline
\end{tabular}

Note $*$ :- Significantly associated at $p<0.30 \& *$ :- Stastically significant at $p<0.05$

P-value of Hosmer and Lemeshow goodness of fit test was $=0.593$ 


\section{Depression Bivariate}

Seizure related trauma

No

Yes

Chronic medical illness

No

Yes

Feeling Perceived stigma

No

Yes

Anxiety

No

Yes

Stress

No

Yes

Physical abused

No

Yes

Sexual abuse

No

Yes

Suicidal attempt

No

Yes

Note $*$ :- Significantly associated at $p<0.30 \&_{* \star}$ :- Stastically significant at $p<0.05$

P-value of Hosmer and Lemeshow goodness of fit test was $=0.593$

$\begin{array}{lll}108 & 54 \quad 1\end{array}$

$85 \quad 49 \quad 0.561 \quad 0.867(0.5371 .402)$

$\begin{array}{lll}166 & 84 & 1\end{array}$

$\begin{array}{llll}27 & 19 & 0.315 & 0.719(0.3781 .368)\end{array}$

$\begin{array}{lll}146 & 47 & 1\end{array}$

$4756 \quad 0.000 * \quad 0.270(0.1630 .449) \quad 0.244(0.129$,

$0.462)^{\star \star}$ 


\section{Depression Bivariate}

Suicidal wish

$\begin{array}{lllll}\text { No } & 155 & 83 & 1 & \\ \text { Yes } & 38 & 20 & 0.955 & 1.017(0.5561 .860)\end{array}$

Contagious belief

No $\begin{array}{lll}169 & 86 & 1\end{array}$

$\begin{array}{lllll}\text { Yes } & 24 & 17 & 0.336 & 0.718(0.3661 .409)\end{array}$

Heritability belief

No $\begin{array}{lll}161 & 74 & 1\end{array}$

Yes $32 \quad 290.020^{*} 0.507(0.2860 .899)$

Belief of mental illness

No $\begin{array}{lll}81 & 34 & 1\end{array}$

Yes 11269

$0.133^{*}$

$0.681(0.4131 .124)$

Treatable belief

$\begin{array}{lllll}\text { No } & 23 & 10 & 0.566 & 1.258(0.5742 .757) \\ \text { Yes } & 170 & 93 & 1 & \end{array}$

Note $*$ :- Significantly associated at $p<0.30 \& *$ :- Stastically significant at $p<0.05$

P-value of Hosmer and Lemeshow goodness of fit test was $=0.593$

\section{Discussion}

The aim of this study was to assess the prevalence of depression and associated factors among people with epilepsy on regular follow up at Ayder comprehensive specialized hospitals \& Mekelle hospital. Overall, the prevalence of depression was found to be $34.8 \%$. $(95 \% \mathrm{Cl}: 29.3,40.2)$

This result was in line with the other study conducted in USA (32.7\%), in United kingdom (30.6\%), in India $(40 \%),(1,10,16)$. The prevalence of depression $(34.8 \%)$ was line with study conducted in Turkey among people with epilepsy (34.7\%) (19). The prevalence of depression among PWE in this study is greater as compared to other study conducted in India (18\%), in Brazil (24.7\%), in Asia (25\%), in Rwanda (26.8\%) and in Nigeria among peoples with epilepsy $(9,17,18,20,45)$. In contrast, the prevalence of depression and anxiety the result of these study (34.8\%) is lower than when compared to the study conducted in west Africa Togo (84\%) and Benin (85.3\%), (45) in Northwest Ethiopia (45.2\%), in central Ethiopia (43.7\%), in 
west Shewa (43\%), in Bench Maji zone (51.2\%) (21-24). The possible explanations for the variation may be due to use of different tools; geographical areas sample size and cultures of the study subject.

Regarding the associated factors, those who are unable to read \& write were more likely to have depression (AOR $=0.400,95 \% \mathrm{Cl}: 0.162,0.986)$ than those who have first degree or above. This study is supported by other studies conducted in Brazil (18), in North west Ethiopia (21) in Bench maji zone (24). The possible explanations might be those individuals with lower educational status might face difficulties socioeconomic stressors like unemployment, poverty and economic dependency and may have poor coping strategies to their illness, which in turn to social isolation, poor adherence to their AEDs, school dropout that impaired their cognition and contributes to poorer psychological adjustment that they face in life.

People with epilepsy who were taking AEDs for at least 11 years were four time more likely to had depression (AOR $=3.715,95 \% \mathrm{Cl}: 1.498,9.212)$ than those who were taking less than 11 months. The possible explanation is patients taking antiepileptic medication may become depressed as a result of their treatment. Because patients starting tiagabine may develop symptoms of agitation, withdrawal, and mood disturbance suggestive of depression.

Those people with epilepsy who hadn't improvement with antiepileptic medication were more like to develop depression (AOR $=0.216,95 \% \mathrm{Cl}$ : $0.101,0.460)$ than those people with epilepsy who had good improvement medication. These results were consistent with the previous studies in Europe (46) in India (17), in North west Ethiopia (21), in Bench Maji zone (24). The possible explanation is those patients who had difficulties of adherence to their AEDs may result in breakthrough seizures that may lead an individual to develop depression.

Those patients who had develop perceived stigma were seventeen times (AOR $=0.244,95 \% \mathrm{Cl}: 0.129$, 0.462 ) more likely to develop depression than those people with epilepsy who had not develop perceived stigma. The result is supported by other studies conducted in Europe (46) in jimma (26) central Ethiopia (22) and in north west Ethiopia (21). This may be due to lack of coping strategies to different seizure effect such as perceived negative social attitude as a result of unaccepted sign of seizure, or the subjects may not develop stigma resistance ability through their life that help them to cope up with different cultural belief, social stigma and the impact of the illness that contributed to felt stigma.

Those patients with high perceived stress had more to had depression ( $\mathrm{AOR}=0.452,95 \% \mathrm{Cl}: 0.220$, 0.928 ) as compared to those patients who had low perceived stress. These results were consistent with the previous studies in Ethiopia $(21,22)$. The possible explanation is that those individual with high perceived stress may have poorer psychological adjustment when they face different stress causing problems such as unemployment, lower educational status, perceived stigma, and seizure frequency \& related trauma in their life that may be precipitate depression disorders.

\section{Conclusion}


This study shows that depression among PWE is the common public health problem. The study also revealed that sociodemographic factors like educational status, clinical related factors like long term intake of medication, poor improvement with medication, stress symptom, perceived stigma were significantly associated with development of depression .

\section{Recommendation}

\section{The researcher recommends to:-}

- Planners and policymakers in collaboration with Ministry of Health to design approach in order to screen frequently co-occurring illness \& to enhance the quality of life of people with epilepsy.

- $\mathrm{MOH}, \mathrm{NGOs}$, Health extension worker and other responsible bodies need to work collaboratively to increase awareness comorbidity of mental illness with chronic health problems including epilepsy by designing campaign.

- Government and non-government sectors to give training for religious institutions, society leaders and parents to increase perception about the nature of epilepsy\& its comorbidity.

- Health professionals need to routinely screen those people with epilepsy for the presence of additional comorbidities and related conditions. It is advised to provide appropriate counselling service or link to respected setting, so that it would be possible to prevent and intervene accordingly.

- The researcher also recommended to further research on depression using different study design, set up and sample size will be conducted in order to investigate future some of the risk factors that were found to be associated with depression among people with epilepsy.

\section{Limitations Of The Study}

Recall and response biases might have occurred when completing the questionnaire. In addition, some of the independent variables like medication adherence, physical \& sexual abuse, presence suicidal wish... were assessed by single questions this may lead some patients to respond in indecorous manner. As a result of using a cross-sectional study design, the researcher was not establishing any cause and effect relationship between the possible determinant of perceived stigma and the outcome of interest.

\section{Declarations}

\section{Ethics approval and consent to participate}

This study was carried out after obtaining ethical approval from Mekelle University, College of Health Science office of Health Research Ethics Review Committee (HRERC) with reference number of Notification of Expedited Approval ERC 1301/2019. Permission letter was obtained from Mekelle University to Psychiatric clinics, and finally, the letter was distributed to health professionals who work in the neurologic clinics and data collectors. Verbal and then written consent form were taken from each participant. For those aged from 12-17, a written assent was taken from their relatives that s/he comes 
with them. An information sheet was attached to each questionnaire to provide study details \& to tell the rights of the participants. All the collected data was used for the purpose of this study only. Hard copy completed questionnaires and computer data was kept confidentially. Decision capacity tool was used.

\section{Consent for publication}

Consent of publication for this research is Mekelle University, College of health science, psychiatry department and participants.

\section{Availability of data and materials}

All availability of data and material are attached on the manuscript.

\section{Competing Interests}

We authors declare that we have no conflict of interest for example on financial support for educational programs, employment or consultation, support from a project sponsor, position on advisory board or board of directors or other type of management relationships and multiple affiliations.

\section{Funding}

Not applicable for this section but the assumption source of funding is Mekelle University, College of Health Science

\section{Authors' contributions}

JS was the principal investigator of the study; made substantial contributions in conception selecting design, supervising \& managing data collection as well as analysis and interpretation of data. KM involved in drafting and revising critically the manuscript. All authors also agreed to be accountable for all aspects of the work in ensuring that questions related to the accuracy or integrity of any part of the work are appropriately investigated and resolved. All authors read and approved the final manuscript.

\section{Acknowledgements}

The authors would like to acknowledge staffs of Mekelle University, study participants, and data collectors for their welcome and assistance and also to Mekelle University School of graduate studies for allowing \& funding to conduct this study. Finally, our special gratitude goes to for all peoples those formally or informally gave us support to accomplish this study.

\section{References}

1. Mbewe EK, Uys LR, Nkwanyana M, Birbeck GL. A primary healthcare screening tool to identify depression and anxiety disorders among people with epilepsy in Zambia. Epilepsy Behav. 2013;27:296-300. 
2. Mbewe EK, Uys LR, Birbeck GL. Detection and management of depression and / or anxiety for people with epilepsy in primary health care settings in Zambia. Seizure Eur J Epilepsy [Internet]. 2013;22(5):401-2. Available from: http://dx.doi.org/10.1016/j.seizure.2013.02.010

3. Mula M. Treatment issues for psychiatric comorbidities of epilepsy Clinical Perspective | Mula. Clin Perspect. 2013;10(3):293-9.

4. Nuckols CC. The Diagnostic and Statistical Manual of Mental Disorders, Fifth Edition ( DSM-5 ). 2013. 343-44 p.

5. Patel RS, Elmaadawi A, Mansuri Z, Kaur M. Psychiatric Comorbidities and Outcomes in Epilepsy Patients: An Insight from a Nationwide Inpatient Analysis in the United States. Cureus 9(9). 2017;9(9).

6. Keezer MR, Sisodiya SM, Sander JW. Comorbidities of epilepsy: current concepts and future perspectives. Lancet Glob Heal [Internet]. 2015;4422(15). Available from: http://dx.doi.org/10.1016/S1474-4422(15)00225-2

7. Al-asmi A, Dorvlo ASS, Burke DT, Al-adawi S, Al-zaabi A, Al-zadjali HAM, et al. The detection of mood and anxiety in people with epilepsy using two-phase designs: Experiences from a tertiary care centre in Oman. Epilepsy Res [Internet]. 2012;98:174-81. Available from: http://dx.doi.org/10.1016/j.eplepsyres.2011.09.012

8. Quiske A, Helmstaedter C, Lux S, Elger CE. Depression in patients with temporal lobe epilepsy is related to mesial temporal sclerosis. Epilepsy Res 39. 2000;39:121-5.

9. Asadi-pooya AA, Kanemoto K, Kwon O, Taniguchi G, Dong Z, Chinvarun Y, et al. Depression in people with epilepsy: How much do Asian colleagues acknowledge it? Seizure Eur J Epilepsy [Internet]. 2018;57:45-9. Available from: https://doi.org/10.1016/j.seizure.2018.03.012

10. Rani R, Arora R, Garg PD, Bala N, Neki NS. Prevalence of psychiatric comorbidities among the patients of epilepsy attending general hospital psychiatric unit. Int J Curr Res Med Sci. 2018;4(5):906.

11. Mammen KANN, S SK. A COMPREHENSIVE REVIEW ON COMORBID DEPRESSION IN PATIENTS WITH EPILEPSY. 2017;10(12).

12. Verrotti A, Carrozzino D, Milioni M, Minna M, Fulcheri M. Epilepsy and its main psychiatric comorbidities in adults and children. J Neurol Sci [Internet]. 2014;343:23-9. Available from: http://dx.doi.org/10.1016/j.jns.2014.05.043

13. Li T. Epilepsy and Associated Comorbidities. Neuropsychiatry (London) (2017). 2017;(1):1-3.

14. Scévola L, Sarudiansky M, Lanzillotti A, Oddo S, Kochen S, Alessio LD. To what extent does depression in fl uence quality of life of people with pharmacoresistant epilepsy in Argentina? Epilepsy Behav. 2017;69:133-8. Available from: http://dx.doi.org/10.1016/j.yebeh.2017.01.007

15. Tegegne MT, Mossie TB, Awoke AA, Assaye AM, Gebrie BT, Eshetu DA. Depression and anxiety disorder among epileptic people at Amanuel Specialized Mental Hospital , Addis Ababa , Ethiopia. BMC Psychiatry [Internet]. 2015;(September). Available from: http://dx.doi.org/10.1186/s12888-0150589-4 
16. Id GD, Mulugeta H, Leshargie CT, Wagnew F, Id SB. Depression among epileptic patients and its association with drug therapy in sub-Saharan Africa: A systematic review and meta-analysis. PLoS One. 2019;14(3).

17. Rehman S, Kalita KK, Baruah A. A hospital based cross sectional study on comorbid psychiatric problems in persons with epilepsy from north eastern part of India. Indian J Rheumatol [Internet]. 2017;4:31-5. Available from: http://dx.doi.org/10.1016/j.ijep.2017.01.004

18. Stefanello S, Marín-léon L, Fernandes PT, Li LM, Botega NJ. Depression and anxiety in a community sample with epilepsy in Brazil. Arq Neuropsiquiatr. 2011;69(2):342-8.

19. Prof A, Balibey H, Yasar H, Prof A, Tekeli H, Balibey $H$, et al. Frequency of Anxiety and Depression in Epileptic Patients. Bull Clin Psychopharmacol. 2015;25(2):136-40.

20. Sezibera V, Nyirasafari D. Incidence of depression in Epilepsy patients. Rwanda Journal, Ser F. 2013;1(1):67-77.

21. Bifftu BB, Dachew BA, Tiruneh BT, Tebeje NB. Depression among people with epilepsy in Northwest Ethiopia: a cross - sectional institution based study. BMC Res Notes. 2015;8(585):1-8.

22. Takele T, Adamu B. Prevalence and Factors Associated to Depression and Anxiety among People with Epilepsy on Follow up at Hospitals in West Shewa Zone, Oromia. J Psychiatry Ment Heal. 2018;3(1).

23. Chaka A, Awoke T, Yohannis Z, Ayano G, Tareke M, Abate A, et al. Determinants of depression among people with epilepsy in Central Ethiopia. Ann Gen Psychiatry [Internet]. 2018;17(27). Available from: https://doi.org/10.1186/s12991-018-0197-z

24. Angelo AT. Prevalence of Depression and its Associated Factors among Adult Epileptic Patients Following Treatment at Selected Public Health Facilities of Bench Maji Zone, South West Ethiopia. Epilepsy J. 2018;4(1):13-6.

25. Bedaso TWJ ebrahim ZY asres. Prevalence of alcohol use disorders and associated factors among people with epilepsy attending Amanuel Mental Specialized Hospital ,. Dovepress. 2016;12:2989-95.

26. Tegegne MT, Mossie TB, Awoke AA, Assaye AM. Depression and anxiety disorder among epileptic people at Amanuel Specialized. BMC Psychiatry [Internet]. 2015;15(210):1-7. Available from: http://dx.doi.org/10.1186/s12888-015-0589-4

27. Kanner AM, Palac S. Depression in Epilepsy: A Common but Often Unrecognized Comorbid Malady. Epilepsy Behav 1,. 2000;51:37-51.

28. Agency CS. THE 2015/16 ETHIOPIAN HOUSEHOLD CONSUMPTION - EXPENDITURE (HCE) SURVEY Central statistical agency. 2018.

29. Rathore JS, Jehi LE, Fan Y, Patel SI, Foldvary-schaefer N, Ramirez MJ, et al. Validation of the Patient Health Questionnaire-9 (PHQ-9) For Depression Screening in Adults with Epilepsy. Epilepsy Behav. 2015;37:215-20.

30. Yeung A, Fung F, Yu S, Vorono S, Ly M, Wu S, et al. Validation of the Patient Health Questionnaire-9 for depression screening among Chinese Americans. Compr Psychiatry. 2008;49:211-7. 
31. Woldetensay YK, Belachew T, Tesfaye M, Spielman K, Biesalski HK, Kantelhardt EJ, et al. Validation of the Patient Health Questionnaire ( PHQ-9) as a screening tool for depression in pregnant women: Afaan Oromo version. 2018;13(2):1-15.

32. Sawaya H, Zeinoun P. Adaptation and initial validation of the Patient Health Questionnaire - 9 ( PHQ9 ) and the Generalized Anxiety Disorder - 7 Questionnaire (GAD-7) in an Arabic speaking Lebanese psyc ... (GAD-7) in an Arabic speaking Lebanese psychiatric outpatient sa. Psychiatry Res. 2016;9:245-52.

33. Prof. Dr. Marcel Tanner, PD Dr. Peter Odermatt PD med. P-MP. EPILEPSY TREATMENT GAP, ASSOCIATED RISK FACTORS AND INTERVENTION STRATEGIES IN KILIFI, KENYA. Epilepsy Behav. 2012;21:39-41.

34. Fanta T, Azale T, Assefa D, Getachew M. Prevalence and Factors Associated with Perceived Stigma among Patients with Epilepsy in Ethiopia. Psychiatry J. 2015;1-8.

35. Tiki TAB and KM. Assessment of the Prevalence and Factors Associated to Perceived Stigma among Epileptic Patient who are on Follow up at Hospitals in West Shewa. J Neurol Neurobiol. 2018;4(2).

36. Nyakwana TDO, Simbauni JA, Jowi JO. Factors Underlying Stigmatization of Epilepsy: A Comparative Case Study of Suba and Meru Central Districts, Kenya. Am Sci Res J Eng Technol Sci. 2014;9(1):88-105.

37. Jemal K. Prevalence and correlates of co-morbid anxiety and depression among patients with dental disease on follow up at Saint Paul's hospital millennium medical college, Addis Ababa, Ethiopia. J Am Sci. 2018;14(3):77-83.

38. Tahir BM, Olabisi AM, Bukar RI, Abba WM, Abayomi OB. A Facility-based Assessment of Internalized Stigma among Patients with Severe Mental Illnesses in. Int Neuropsychiatr Dis J. 2016;6(1):1-11.

39. Seo J, Park S. Validation of the Generalized Anxiety Disorder-7 (GAD-7) and GAD-2 in patients with migraine. J Headache Pain. 2015;16(97).

40. Bekele S, Mulugeta D. Depression, Anxiety and Stress among First Year Addis Ababa University Students: Magnitude, and Relationship with Academic Achievement. J Heal Med Nurs. 2018;56:539.

41. Jack J. Lin, Marco Mula and BPH. Uncovering the Lifespan Neurobehavioral Comorbidities of Epilepsy. Lancet. 2013;380(9848):1180-92.

42. Fisher RS, Acevedo C, Arzimanoglou A, Bogacz A, Cross JH, Elger CE, et al. ILAE OFFICIAL REPORT A practical clinical definition of epilepsy. Epilepsia, 55(4):475-482,. 2014;55(4):475-82.

43. Veldwijk J, Proper KI, Hoeven-mulder HB, Bemelmans WJE. The prevalence of physical, sexual and mental abuse among adolescents and the association with BMI status. BMC Public Health. 2012;12(840).

44. American Psychiatric Association. Diagnostic and statistical manual of mental disorders. 5th ed.Washington, DC:American Psychiatric Association. 2013.

45. Owolabi SD, Femi L, Udofia O, Sale S. Depression in patients with epilepsy in Northwestern Nigeria: Prevalence and clinical correlates. Ann african Med. 2016;15(4):179-84. 
46. Kwon O, Park S. Depression and Anxiety in People with Epilepsy. J Clin Neurol. 2014;10(3):175-88.

\section{Figures}

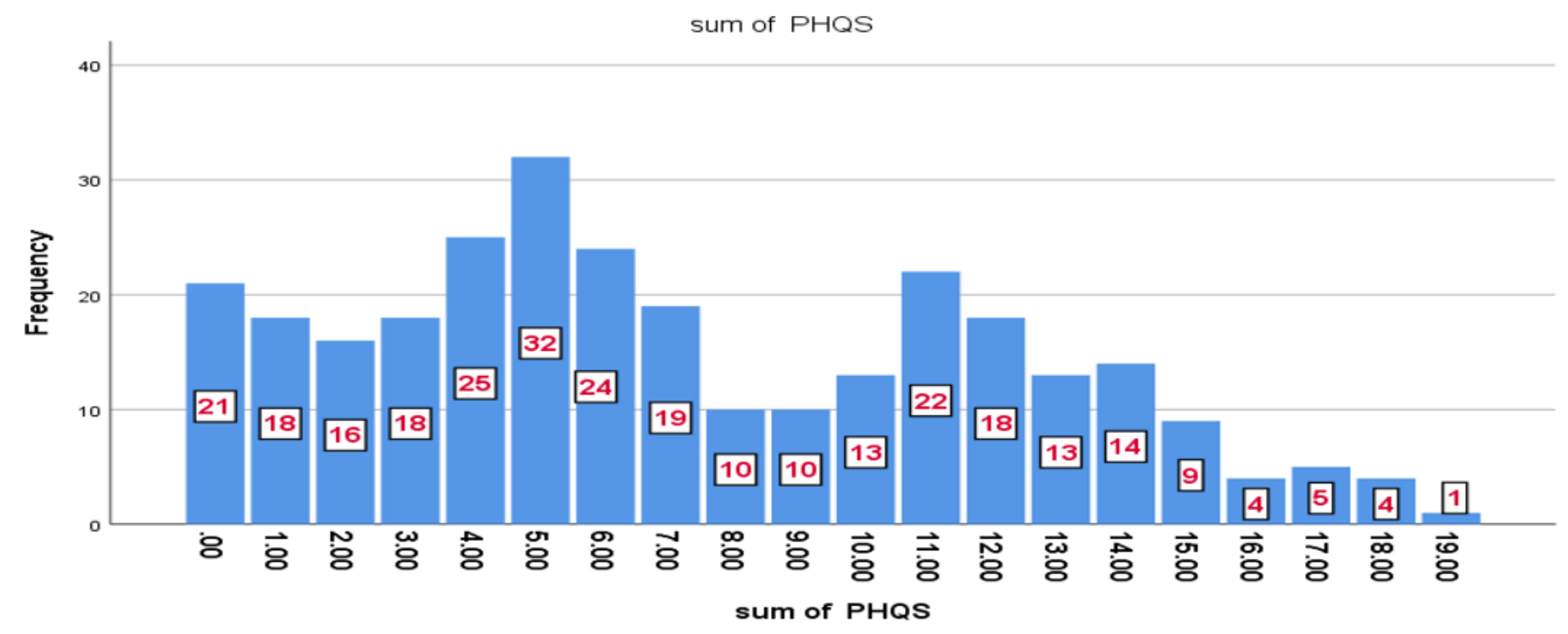

\section{Figure 1}

The frequency of the sum of patient health questionnaire response of the study depression and associated factors among PWE $(\mathrm{n}=296)$ on follow up at Ayder comprehensive specialized hospital and Mekelle hospital, Mekelle, Tigray, Ethiopia, 2019 


\section{catagory of sum of PHQs}

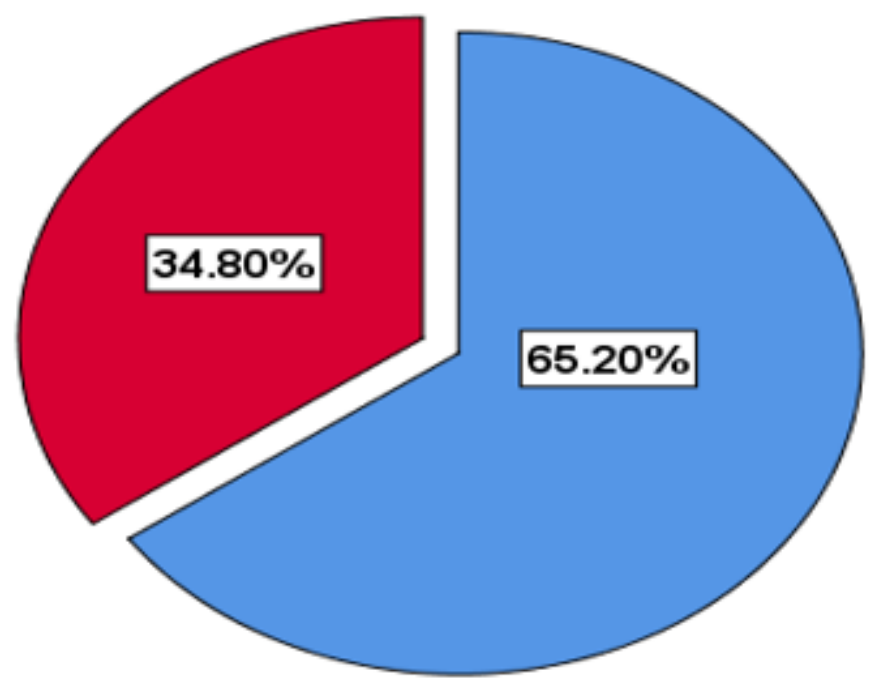

\section{Figure 2}

Prevalence of depression among people with epilepsy $(n=296)$ on follow up at Ayder comprehensive specialized hospital and Mekelle hospital, Mekelle, Tigray, Ethiopia, 2019. 